\title{
COERÊNCIA TERMODINÂMICA DO PADRÃO ESPACIAL DE CHUVAS PREVISTO PELO MODELO WRF DURANTE O PROJETO CHUVA - ESTAÇÃO ALCÂNTARA 2010
}

\author{
Adaiana F. Gomes da Silva ${ }^{1}{ }_{*}$; Gilberto Fisch ${ }^{2}$ \\ ${ }^{1}$ Instituto Nacional de Pesquisas Espaciais (CPTEC/INPE) - São José dos Campos - SP \\ ${ }^{2}$ Instituto de Aeronáutica e Espaço (IAE) - São José dos Campos - SP \\ adaiana1@yahoo.com.br, fisch.gilberto@gmail.com
}

\section{RESUMO}

Foi avaliada a capacidade do modelo WRF-ARW (versão 3.2.1) em prever o padrão espacial de chuvas na região do Centro de Lançamento de Alcântara durante o período do Projeto Chuva neste local (março de 2010). Previsões de 72 horas com resolução horizontal máxima de $1 \mathrm{~km}$ e vertical de 42 níveis tiveram suas saídas horárias comparadas com imagens de radar meteorológico em modo PPI e dados de pluviômetro. No geral, o modelo não foi bom em capturar a presença de chuva em termos de posicionamento e intensidade, sendo esta sempre muito subestimada.

\section{INTRODUÇÃO}

O Centro de Lançamento de Alcântara (CLA) é considerado o "portal brasileiro para o espaço", sendo o local de lançamento de foguetes tais como o Veículo Lançador de Satélites (VLS) e foguetes de sondagem (VSB30, por exemplo). O CLA está localizado na região nordeste brasileira, no norte do Estado do Maranhão, próximo de sua capital, São Luís, à latitude de $2^{\circ} \mathrm{S}$. Segundo Fisch (1999), durante a estação chuvosa da região (janeiro a junho), o fenômeno de brisa marítima é menos intenso devido ao menor contraste térmico entre o oceano e o continente e o vento é formado basicamente pelos alísios. Por isso, no geral, é mais fraco.

Silva (2013) realizou um estudo sobre a determinação dos ventos no CLA pelo modelo WRF (Weather Research and Forecasting) comparando com observações de radiossondagens, e concluiu que o modelo foi razoável para a previsão do vento. Porém, sabe-se que os padrões de chuva podem interferir nos campos de escoamento. Por isto, o trabalho atual teve o objetivo de avaliar a performance do modelo WRF na previsão do padrão espacial de chuvas através da comparação com dados de radar banda-X para um período representativo da estação chuvosa (ventos fracos). A motivação é tornar o modelo operacional no Setor de Meteorologia do CLA, para que este possa realizar previsões locais autônomas e de qualidade às vésperas de uma operação de lançamento de foguete, buscando aumentar a segurança da operação.

\section{DADOS E MÉTODOS}

O modelo atmosférico WRF, núcleo ARW (Advanced Research WRF), foi inicializado com dados gerados pela previsão do modelo global GFS, do National Center of Atmospheric Research (NCEP), com resolução espacial de $0,5^{\circ}$ x $0,5^{\circ}$ e temporal de 6 horas. Os dados do terreno foram fornecidos pelo United States Geological Survey (USGS), com resolução espacial de 30" de arco. Todas as simulações foram realizadas com 42 níveis na vertical, três domínios quadrados e centralizados no CLA com dimensões de 900, 264 e 76

* Atualmente em Instituto Tecnológico de Aeronáutica (ITA) - São José dos Campos - SP. 
$\mathrm{km}^{2}$, sendo um domínio mãe e dois aninhados, com comunicação bidirecional de dados entre eles. O espaçamento da grade do domínio maior foi de $9 \times 9 \mathrm{~km}$, reduzindo na proporção de 3 até a grade de 1x1 km no domínio menor. A parametrização de microfísica utilizada foi a WRF Single Moment 3-class e para CLP, MYNN2,5. Simulações com tempo de integração de 72 horas, incluso o tempo inicial de spin-up de 6 horas, foram iniciadas a cada 12 horas (às 00 e às 12 UTC) ao longo dos dias 19 a 25/03/2010. Os parâmetros numéricos e físicos adotados foram definidos por uma série de testes iniciais de sensibilidade, não abordados em detalhes neste texto. Maiores informações e resultados podem ser encontrados em Silva (2013).

Foram utilizados dados de pluviômetro e imagens do Radar Banda X, em operação no experimento Chuva Alcântara GPM 2010 e disponíveis no portal do projeto. As imagens (em dBz) geradas a cada intervalo de 6 minutos com raios de alcance de 30 e $120 \mathrm{~km}$ foram comparadas com campos de precipitação acumulada de saídas horárias das simulações do WRF (mm/h) para o domínio interno de maior resolução. Para compensar a diferença entre os valores acumulados pelo modelo ao longo de 1 hora e os valores instantâneos do radar, todas as imagens do radar no intervalo entre determinada hora e sua antecedente foram utilizadas para a análise. Isto permitiu, de acréscimo, rastrear a trajetória de sistemas convectivos de escala maior, que se deslocavam sobre a área do domínio de simulação.

\section{RESULTADOS E CONSIDERAÇÕES FINAIS}

Com relação às imagens de radar, o modelo WRF não conseguiu posicionar corretamente os núcleos de chuva tanto no espaço quanto no tempo, assim como também não foi eficiente em representar as intensidades de precipitação. Foram verificadas diversas defasagens de tempo, de 1 a 2 horas ou mais. Quando ocorreu o posicionamento correto de núcleos de chuva, sua intensidade foi sempre muito subestimada pelo modelo. Devido à metodologia utilizada, não foi possível quantificar com precisão a quantidade de chuva subestimada.

Dentre todas as simulações realizadas e analisadas, um exemplo que merece destaque foi a forte precipitação observada pelo radar sobre o CLA durante 15 horas praticamente ininterruptas, das 16 UTC do dia 21 às 07 UTC do dia 22 de março de 2010, com núcleos de até $60 \mathrm{dBz}$, equivalente a aproximadamente $100 \mathrm{~mm} / \mathrm{h}$. Nenhuma das rodadas que incluíram este intervalo temporal foi capaz de representar tal evento extremo. Somente após o cessar das chuvas observadas o modelo começou a representar fortes núcleos aos arredores do CLA, mas representando no máximo $30 \mathrm{~mm} / \mathrm{h}$ e deslocados, já que o núcleo principal foi observado sobre o CLA. É possível que o modelo global (GFS) tenha carregado este atraso em seus arquivos de previsão, utilizados como dados de entrada.

Outro exemplo é o sistema convectivo representado pelo WRF no acumulado entre 12 e 13 UTC do dia 22 de março. Analisando as imagens de radar em horários próximos, tanto anteriores quanto posteriores, percebeu-se que os núcleos se assemelhavam com as observações do sistema que passou pela região de Alcântara entre 10 e 12 UTC. Ou seja, o modelo WRF representou a chuva com atraso de aproximadamente 2 horas. Isto pode ser um indicativo de que as nuvens estavam se deslocando mais rapidamente do que calculado pelo modelo WRF, mostrando uma defasagem temporal.

A fim de obter um resultado mais quantitativo, foram gerados gráficos de precipitação acumulada pontualmente sobre o CLA com dados observados de pluviômetro e saídas do WRF. Os resultados foram absolutamente negativos. As distribuições temporais não coincidem e as estimativas do WRF são sempre mais baixas do que o observado em 
qualquer horário. Como exemplo, na simulação iniciada às $00 \mathrm{Z}$ do dia 20 a precipitação máxima estimada pelo modelo ao longo do dia 21 foi de $0,9 \mathrm{~mm} / \mathrm{h}$, enquanto houve observação de até $32 \mathrm{~mm} / \mathrm{h}$. Na simulação iniciada dia 24, 00Z, o modelo não capturou nenhuma precipitação ao longo deste dia 24, enquanto houve observação de até $14 \mathrm{~mm} / \mathrm{h}$.

Desta forma, conclui-se que o modelo WRF, com a configuração default de microfísica de nuvens utilizada, não consegue capturar a presença de chuva em termos de posicionamento e intensidade.

\section{REFERÊNCIAS BIBLIOGRÁFICAS}

FISCH, G. Características do perfil vertical do vento no Centro de Lançamento de foguetes de Alcântara (CLA). Revista Brasileira de Meteorologia, v. 14, n. 1, p. 11-21, 1999. SILVA, A. F. G. Avaliação do modelo WRF ao perfil do vento no Centro de Lançamento de Alcântara. 2013. 98 p. Dissertação (Mestrado em Meteorologia) - Instituto Nacional de Pesquisas Espaciais (INPE), São José dos Campos, 2013. 